\title{
Analisis Persepsi Masyarakat terhadap Pengelolaan Kawasan Mangrove Teluk Kotania
}

\author{
Hellen Nanlohy ${ }^{1}$ \\ Program Doktor Manajemen Sumber Daya Pantai \\ Universitas Diponegoro, Semarang, Indonesia
}

\section{Azis Nur Bambang}

Fakultas Perikanan dan IImu Kelautan, Universitas Diponegoro, Semarang, Indonesia

\section{Ambaryanto}

Fakultas Perikanan dan IImu Kelautan, Universitas Diponegoro, Semarang, Indonesia

\section{Sahala Hutabarat}

Fakultas Perikanan dan IImu Kelautan, Universitas Diponegoro, Semarang, Indonesia

\begin{abstract}
Abstrak: Pembangunan wilayah pesisir berkembang dengan pesat seiring dengan pertumbuhan penduduk yang cukup tinggi akan mengancam kelangsungan kawasan dan ekosistem pesisir. Kawasan mangrove yang berada di wilayah pesisir di teluk Kotania menjadi kawasan yang mendapat tekanan secara ekologis yang sangat mempengaruhi kelestariannya. Kesadaran masyarakat pesisir sangat penting dalam upaya pelestarian kawasan mangrove. Penelitian ini dilakukan dengan tujuan untuk menganalisis kesadaran masyarakat terhadap pengelolaan kawasan mangrove secara berkesinambungan dan lestari. Metode yang digunakan adalah penelitian survei pada lima dusun di teluk Kotania dengan metode deskritif yang bersifat studi kasus dan pembagian persepsi atas sepuluh kategori penilaian, data dikumpulkan melalui wawancara, observasi dan didukung oleh data sekunder. Deskripsi penelitian ini dengan memfokuskan pada persepsi masyarakat dalam pengelolaan kawasan mangrove teluk Kotania. Analisa data digunakan pendekatan secara deskritif kualitatif yang menggunakan rataan skor dengan rentang skala.Hasil analisis menunjukkan bahwa sebahagian besar masyarakat pesisir di teluk Kotania sangat setuju bahwa; 1) Kawasan mangrove di Teluk Kotania saat ini perlu/penting untuk dikelola agar dapat lestari, 2) Bentuk pengelolaan kawasan mangrove yang dilakukan harus melibatkan seluruh penduduk setempat, 3) Perlu adanya kerjasama antara pemerintah dan masyarakat setempat dalam kegiatan pengelolaan kawasan mangrove.
\end{abstract}

Kata Kunci: mangrove, masyarakat pesisir, pengelolaan, persepsi

\begin{abstract}
Coastal development is growing rapidly due to high population growth. This condition will threaten the sustainability of the region and coastal ecosystems. The goal from this research is to analyze the perception of community towards sustainable coastal management. This research used survey method with case study. The research was conducted in the five villages in Teluk Kotania. Techniques of data collection using
\end{abstract}

\footnotetext{
${ }^{1}$ Korespondensi Penulis: Program Doktor Manajemen Sumber Daya Pantai, Universitas Diponegoro, Semarang Email: nanlohy_hellen@yahoo.com
} 
interviews, observation, and secondary data. Data analyzed by qualitatif description with average scor and distance scale. The analysis shows that coastal communities in teluk Kotania are very agree for 1) region mangrove management order that preserve; 2) people's partisipation were very important to region mangrove management; and then 3) Goverment and coastal people's must be work together to region mangrove management.

Keywords : coastal community, management, mangrove, perception

\section{Pendahuluan}

Pengelolaan wilayah pesisir biasanya dilakukan secara sektoral berkaitan dengan pengelolaan pada satu macam pemanfaatan sumberdaya pesisir yang dilakukan oleh satu instansi pemerintah. Pengelolaan wilayah pesisir ini mempunyai tujuan tertentu namun dalam pelaksanaannya kurang mempertimbangkan aspek ekologis, geografis, dan sosial budaya, diikuti rendahnya persepsi masyarakat. Pengelolaan semacam ini dapat menimbulkan konflik kepentingan antar sektor yang berkepentingan dalam melakukan aktivitas pembangunan pada wilayah pesisir yang sama. Selain itu, pendekatan sektoral semacam ini umumnya kurang memperhatikan dampak terhadap pengelolaan sumberdaya yang lain, sehingga dapat mematikan usaha di sektor lain (Dahuri, et al, 2004).

Wilayah pedesaan Maluku yang didominasi oleh lautan menyebabkan masyarakat yang tinggal di sekitar pesisir memiliki ketergantungan hidupnya terhadap sumberdaya pesisir dan laut. Pertumbuhan penduduk yang cukup tinggi mendorong tumbuhnya berbagai kegiatan pemanfaatan sumberdaya pesisir. Hal ini akan berdampak positif terhadap peningkatan kondisi perekonomian masyarakat, namun di sisi lain hal ini dapat menyebabkan berbagai dampak negatif. Adanya kegiatan pemanfaatan sumberdaya pesisir akan mengakibatkan kerusakan lingkungan (Fauzi dan Anna, 2005; Mulyadi, 2007; Supriharyono, 2009; Harahap, 2010; Tuwo, 2011).

Teluk Kotania merupakan bagian dari perairan Kabupaten Seram Bagian Barat, dengan luas perairan $470.999 \mathrm{~km}^{2}$ dan kedalaman 0-200 m. Teluk ini berbentuk permanen tertutup dan sangat menarik dijadikan sebagai objek penelitian, dan memiliki sumberdaya pesisir dan laut seperti mangrove, padang lamun, terumbu karang dan berbagai jenis ikan. Wilayah pesisir dan lautnya dimanfaatkan untuk kegiatan perikanan tangkap, budidaya, pariwisata maupun ekowisata.

Kawasan mangrove di wilayah teluk Kotania saat ini dimanfaatkan masyarakat untuk memenuhi kebutuhan hidup masyarakat sehari-hari. Kondisi ini menimbulkan terjadinya dampak negatif yaitu terjadinya degradasi mangrove dari tahun ke tahun (Nanlohy, et al., 2013). Salah satu upaya yang dilakukan untuk mengurangi dampak negatif pemanfaatan mangrove yang berlebihan adalah dengan melalui perencanaan pengelolaan kawasan mangrove. Perencanaan pengelolaan kawasan mangrove ini harus dimulai dari kesadaran dan persepsi masyarakat yang berada di wilayah teluk Kotania terhadap pengelolaan kawasan mangrove tersebut.

Peningkatan kesadaran masyarakat dalam pengelolaan suatu kawasan sangat penting demi keberhasilan upaya pengelolaan kawasan tersebut (Dian, A., N., dan Hapsari, T., 2012). Analisis persepsi masyarakat pesisir akan sangat menentukan apakah masyarakat mengerti tentang kawasan mangrove bagi kelangsungan hidup masyarakat dan lingkungan pesisir dalam kaitan dengan pengelolaan kawasan mangrove tersebut agar tetap lestari.

Tujuan dari penelitian ini adalah untuk menganalisis persepsi masyarakat pesisir terhadap pengelolaan kawasan mangrove. 


\section{Metodologi}

Penelitian ini berlangsung dari Januari - Maret 2013. Lokasi penelitian berada pada dusun Kotania bawah, dusun Wael, dusun Airpessy, dusun Taman Jaya dan dusun Pulau Osi. Penelitian ini adalah penelitian survei dengan metode deskritif yang bersifat studi kasus. Deskripsi penelitian ini adalah memfokuskan pada persepsi masyarakat dalam pengelolaan kawasan mangrove teluk Kotania.

Variabel penelitian ini adalah penekanan pada kriteria persepsi masyarakat tentang pengelolaan kawasan mangrove. Variabel persepsi penilaian masyarakat ini dijabarkan dalam sepuluh kriteria penilaian.

Populasi dan sampel yang digunakan disesuaikan dengan ruang lingkup dan tujuan riset Populasi adalah keseluruhan subjek penelitian (Arikunto, 2010). Populasi dalam penelitian ini adalah keseluruhan masyarakat pesisir yang memanfaatkan kawasan mangrove secara ekonomi. Populasi dalam penelitian ini berjumlah 943 kepala keluarga yang menempati kelima lokasi penelitian dan melakukan aktivitas memanfaatkan eksosistem mangrove. Subjek dalam penelitian ini bersifat homogen, sehingga dilakukan pengambilan sampel secara representatif dan penarikan sampel dilakukan secara random atau acak. Jumlah sampel yang diambil ditentukan berdasarkan persamaan yang dikemukakan oleh Ernawati, (1997) sebagai berikut:

$$
\mathrm{n}=\frac{\mathrm{N}}{\mathrm{N} \mathrm{d}^{2}+1}
$$

Dimana: $\mathrm{n}=$ Jumlah sampel

$$
\begin{aligned}
& \mathrm{N}=\text { Jumlah populasi } \\
& \mathrm{d}=\text { Derajat kesalahan }
\end{aligned}
$$

Pemilihan responden dilakukan dengan metode purposive sampling, berdasarkan pertimbangan dan tujuan untuk mengetahui persepsi masyarakat dalam pengelolaan kawasan mangrove. Responden yang diambil seluruhnya adalah masyarakat yang memanfaatkan kawasan mangrove dalam memenuhi kebutuhan hidup sehari-hari.

Pengumpulan data, menggunakan data primer dan data sekunder. Data primer diperoleh dengan cara wawancara menggunakan kuisioner serta observasi. Data sekunder diperoleh dari berbagai tulisan dan sumber-sumber data lainnya yang relevan dengan penelitian ini.

Analisa data digunakan pendekatan secara deskritif kualitatif dan, formulasinya sebagai berikut :

1. Rataan skor $=$

$$
\bar{X}=\sum\left(\frac{\text { Skor pertanyaan } \times \text { frekuensi skor }}{n}\right)
$$

2. Rentang skala $=$

$R_{s}=\frac{(m-1)}{m}$

Dimana:

$\mathrm{N}=$ jumlah sampel

$\mathrm{m}=$ jumlah alternatif jawaban tiap item

\section{Langkah 1:}

Menentukan rentang skala, yakni: 


$$
\begin{aligned}
& R_{s}=\frac{(m-1)}{m} \\
& R_{s}=\frac{(5-1)}{5} R_{s}=\frac{(4-1)}{5}=0,8
\end{aligned}
$$

\section{Langkah 2:}

Posisi keputusan penilaian adalah:

Tabel 1. Skor Rataan Penilaian Persepsi Masyarakat

\begin{tabular}{|c|c|}
\hline Skor Rataan & Keterangan \\
\hline $1,0-1,8$ & Sangat Tidak Setuju \\
\hline $1,8-2,6$ & Tidak Setuju \\
\hline $2,6-3,4$ & Ragu-Ragu \\
\hline $3,4-4,2$ & Setuju \\
\hline $4,2-5,0$ & Sangat Setuju \\
\hline
\end{tabular}

Sumber : Umar, 2005

\section{Temuan dan Kajian}

Dilihat dari fungsi ekologis kawasan mangrove mempunyai arti yang sangat penting. Berbagai jenis biota laut yang hidup di kawasan mangrove teluk Kotania sangat bergantung pada eksistensi kawasan mangrove. Perairan mangrove dikenal berfungsi sebagai tempat asuhan (nursery ground) bagi berbagai jenis hewan akuatik yang mempunyai nilai ekonomi penting, seperti ikan, udang, dan kerang-kerangan. Selain itu, luruhan daun mangrove di kawasan mangrove merupakan sumber bahan organik yang penting dalam rantai pakan (food chain) di dalam lingkungan perairan dimana produksi luruhan daun dapat mencapai 7-8 ton/ha/tahun (Nontji, 2000).

Kawasan mangrove merupakan habitat (rumah) bagi berbagai jenis burung, reptilia, mamalia dan jenis-jenis kehidupan lainnya, sehingga kawasan mengrove menyediakan keanekaragaman (biodiversity) dan plasma nutfah yang tinggi serta berfungsi sebagai sistem penunjang kehidupan. Dilihat dari fungsi fisik, maka dengan sistem perakaran dan kanopi yang rapat serta kokoh, kawasan mangrove juga berfungsi sebagai pelindung daratan dari gempuran gelombang, tsunami, angin topan, perembesan air laut dan gayagaya dari laut lainnya. Selanjutnya dinyatakan bahwa potensi ekonomi mangrove diperoleh dari tiga sumber utama, yaitu hasil kawasan, perikanan estuarin dan pantai, serta wisata alam. Selain itu, kawasan mangrove dapat dimanfaatkan kayunya secara lestari untuk bahan bangunan, arang (charcoal) dan bahan baku kertas. Kawasan mangrove juga merupakan pemasok larva ikan, udang dan biota laut lainnya.

Kawasan mangrove teluk Kotania mempunyai nilai ekonomi yang cukup tinggi, dengan total nilai pemanfaatan Rp. 526.397.030/ tahun (Nanlohy, H., et al., 2013) jika dibandingkan dengan beberapa kawasan mangrove di Maluku berdasarkan beberapa hasil penelitian sebagai berikut; total nilai ekonomi kawasan mangrove desa/negeri Tawiri sebesar Rp. 63.257.034/tahun (Soukotta, L., M., 2013); total nilai ekonomi kawasan mangrove desa/negeri Passo sebesar Rp. 185.800.570/tahun (Talakua, W., 2013) dan total nilai ekonomi kawasan mangrove desa/negeri Waiheru sebesar Rp. 285.543.161/thn (Nanlohy, H., 2013).

Tingginya nilai ekonomi kawasan mangrove di teluk Kotania harus dapat dipertahankan agar kawasan mangrove beserta dengan ekosistem yang berada di kawasan 
mangrove tetap terjaga dan lestasi. Kelestarian kawasan mangrove beserta ekosistim yang berada di kawasan mangrove ini harus dijaga oleh masyarakat setempat. Persepsi masyarakat perlu diarahkan dan dikembangkan untuk menjaga kelestarian kawasan mangrove tersebut.

\section{Persepsi Masyarakat Terhadap Pengelolaan Kawasan Mangrove di Teluk Kotania}

Masyarakat yang berdiam di wilayah pesisir harus merasa memiliki dan bertanggung jawab untuk menjaga kelestarian sumberdaya berkelanjutan (Dian, A. N., dan Trisnani D. H., 2012). Untuk mencapai tujuan tersebut maka masyarakat pesisir perlu dukungan kualitas sumberdaya manusia sebagai subjek dalam pengelolaan kawasan pesisir.

Ada sepuluh kriteria penilaian yang digunakan untuk menganalisis persepsi masyarakat di teluk Kotania terhadap pengelolaan kawasan mangrove. Kriteria tersebut adalah sebagai berikut :

1. Kawasan mangrove di Teluk Kotania saat ini perlu/penting untuk dikelola agar dapat lestari (P1).

2. Bentuk pengelolaan kawasan mangrove yang dilakukan harus melibatkan seluruh penduduk setempat (P2).

3. Perlu adanya kerjasama antara pemerintah dan penduduk setempat dalam kegiatan pengelolaan kawasan mangrove (P3).

4. Perlu adanya aturan dalam pengelolaan kawasan mangrove (P4).

5. Pelanggaran terhadap aturan pengelolaan kawasan mangrove perlu diberikan sanksi atau hukuman (P5).

6. Bentuk pengelolaan tidak harus sesuai dengan kearifan lokal (adat istiadat/budaya) yang dimiliki penduduk setempat (P6).

7. Pengelolaan kawasan mangrove di Teluk Kotania akan menghambat pembangunan wilayah pesisir dan laut. Misalnya: pembangunan perumahan penduduk dan lahan pertanian akan terhambat (P7).

8. Pengelolaan kawasan mangrove akan membatasi penduduk setempat untuk memanfaatkan mangrove maupun sumber daya yang ada didalamnya (P8).

9. Hanya sebagian penduduk setempat atau pemerintah saja yang akan memperoleh manfaat/keuntungan atas adanya pengelolaan kawasan mangrove di Teluk Kotania (P9).

10. Masyarakat pendatang tidak perlu menaati aturan dalam pengelolaan kawasan mangrove di Teluk Kotania (P10).

Kesepuluh kriteria tersebut kemudian diskoring berdasarkan penilaian masyarakat untuk mengidentifikasi posisi keputusan penilaian persepsi masyarakat dan keputusan penilaian didasarkan pada skor rataan. Berdasarkan posisi (indicator) pengambilan keputusan dan dibandingkan dengan nilai rata-rata skor tiap pertanyaan persepsi maka hasil persepsi masyarakat di teluk Kotania dapat dijabarkan untuk setiap dusun pada Tabel 2 berikut ini.

Tabel 2. Kriteria Penilaian Persepsi Responden Per Dusun Terhadap Pengelolaan Kawasan Mangrove di Teluk Kotania

\begin{tabular}{l|c|c|c|c|c|c|c|c|c|c}
\hline \multirow{2}{*}{ Dusun } & \multicolumn{10}{c}{ KRITERIA PENILAIAN } \\
\cline { 2 - 12 } & P1 & P2 & P3 & P4 & P5 & P6 & P7 & P8 & P9 & P10 \\
\hline Pulau Osi & $\mathbf{4 , 5}$ & $\mathbf{4 , 3 7}$ & $\mathbf{4 , 4}$ & $\mathbf{4 , 1 7}$ & $\mathbf{3 , 5 7}$ & $\mathbf{2 , 7 3}$ & $\mathbf{3 , 2 7}$ & $\mathbf{3 , 3 3}$ & $\mathbf{3 , 6 3}$ & $\mathbf{3 , 4}$ \\
\hline Kotania & $\mathbf{4 , 5 3}$ & $\mathbf{4 , 4 3}$ & $\mathbf{4 , 4 3}$ & $\mathbf{4 , 0 7}$ & $\mathbf{3 , 8 3}$ & $\mathbf{3}$ & $\mathbf{3 , 6}$ & $\mathbf{3 , 5 7}$ & $\mathbf{3 , 6 7}$ & $\mathbf{4}$ \\
\hline
\end{tabular}




\begin{tabular}{l|c|c|c|c|c|c|c|c|c|c}
\hline \multirow{2}{*}{ Dusun } & \multicolumn{10}{|c}{ KRITERIA PENILAIAN } \\
\cline { 2 - 11 } & P1 & P2 & P3 & P4 & P5 & P6 & P7 & P8 & P9 & P10 \\
\hline Wael & $\mathbf{4 , 4}$ & $\mathbf{4 , 3}$ & $\mathbf{4 , 2 3}$ & $\mathbf{4 , 0 7}$ & $\mathbf{3 , 7 3}$ & $\mathbf{3 , 6 3}$ & $\mathbf{3 , 4 7}$ & $\mathbf{3 , 7 3}$ & $\mathbf{3 , 9 7}$ & $\mathbf{3 , 9 7}$ \\
\hline Airpessy & $\mathbf{4 , 4}$ & $\mathbf{4 , 3 7}$ & $\mathbf{4 , 3 7}$ & $\mathbf{4 , 2}$ & $\mathbf{4 , 1}$ & $\mathbf{3 , 5}$ & $\mathbf{3 , 9}$ & $\mathbf{3 , 9 7}$ & $\mathbf{4 , 1}$ & $\mathbf{4 , 2 7}$ \\
\hline $\begin{array}{l}\text { Taman } \\
\text { Jaya }\end{array}$ & $\mathbf{4 , 8 3}$ & $\mathbf{4 , 2}$ & $\mathbf{4 , 2}$ & $\mathbf{4 , 2}$ & $\mathbf{4 , 1 7}$ & $\mathbf{2 , 8 3}$ & $\mathbf{1 , 6 3}$ & $\mathbf{1 , 8}$ & $\mathbf{1 , 8}$ & $\mathbf{1 , 6 7}$ \\
\hline
\end{tabular}

Berdasarkan hasil analisis persepsi masyarakat terhadap pengelolaan kawasan mangrove di masing-masing dusun seperti terlihat pada tabel diatas maka secara keseluruhan hasil persepsi masyarakat di Teluk Kotania dapat dilihat pada tabel berikut ini.

Tabel 3. Penilaian Persepsi Mansyarakat terhadap Pengelolaan Kawasan Mangrove di Teluk Kotania

\begin{tabular}{|c|c|c|c|}
\hline No. & Kriteria Penilaian & $\begin{array}{l}\text { Nilai Skor } \\
\text { Rata-rata }\end{array}$ & Keterangan \\
\hline $\mathrm{P} 1$ & $\begin{array}{l}\text { Kawasan mangrove di Teluk Kotania saat ini } \\
\text { perlu/penting untuk dikelola agar dapat lestari. }\end{array}$ & 4,532 & Sangat Setuju \\
\hline $\mathrm{P} 2$ & $\begin{array}{l}\text { Bentuk pengelolaan kawasan mangrove yang } \\
\text { dilakukan harus melibatkan seluruh penduduk } \\
\text { setempat }\end{array}$ & 4,334 & Sangat Setuju \\
\hline $\mathrm{P} 3$ & $\begin{array}{l}\text { Perlu adanya kerjasama antara pemerintah dan } \\
\text { penduduk setempat dalam kegiatan pengelolaan } \\
\text { kawasan mangrove }\end{array}$ & 4,326 & Sangat Setuju \\
\hline $\mathrm{P} 4$ & $\begin{array}{l}\text { Perlu adanya aturan dalam pengelolaan kawasan } \\
\text { mangrove. }\end{array}$ & 4,142 & Setuju \\
\hline P5 & $\begin{array}{l}\text { Pelanggaran terhadap aturan pengelolaan kawasan } \\
\text { mangrove perlu diberikan sanksi atau hukuman. }\end{array}$ & 3,88 & Setuju \\
\hline P6 & $\begin{array}{l}\text { Bentuk pengelolaan tidak harus sesuai dengan } \\
\text { kearifan lokal (adat istiadat/budaya) yang dimiliki } \\
\text { penduduk setempat }\end{array}$ & 3,138 & Ragu-ragu \\
\hline $\mathrm{P} 7$ & $\begin{array}{l}\text { Pengelolaan kawasan mangrove di Teluk Kotania } \\
\text { akan menghambat pembangunan wilayah pesisir } \\
\text { dan laut. Misalnya: pembangunan perumahan } \\
\text { penduduk dan lahan pertanian akan terhambat }\end{array}$ & 3,174 & Ragu-ragu \\
\hline P8 & $\begin{array}{l}\text { Pengelolaan kawasan mangrove akan membatasi } \\
\text { penduduk setempat untuk memanfaatkan mangrove } \\
\text { maupun sumber daya yang ada didalamnya. }\end{array}$ & 3,28 & Ragu-ragu \\
\hline P9 & $\begin{array}{l}\text { Hanya sebagian penduduk setempat atau } \\
\text { pemerintah saja yang akan memperoleh } \\
\text { manfaat/keuntungan atas adanya pengelolaan } \\
\text { kawasan mangrove di Teluk Kotania. }\end{array}$ & 3,434 & Setuju \\
\hline 20 & $\begin{array}{l}\text { Masyarakat pendatang tidak perlu mentaati aturan } \\
\text { dalam pengelolaan kawasan mangrove di Teluk } \\
\text { Kotania }\end{array}$ & 3,462 & Setuju \\
\hline
\end{tabular}

Hasil analisis pada Tabel 3 menunjukkan bahwa masyarakat pesisir di teluk Kotania sangat setuju bahwa; 1) Kawasan mangrove di Teluk Kotania saat ini perlu/penting untuk dikelola agar dapat lestari, 2) Bentuk pengelolaan kawasan mangrove yang dilakukan harus melibatkan seluruh penduduk setempat, 3) Perlu adanya kerjasama antara pemerintah dan penduduk setempat dalam kegiatan pengelolaan kawasan mangrove. Berdasarkan hasil analisis persepsi terhadap tiga kriteria diatas menunjukkan bahwa masyarakat pesisir teluk Kotania mengerti 
pentingnya kawasan mangrove dalam keberlangsungan hidup mereka. Mereka menyadari bahwa kawasan mangrove perlu dikelola dengan baik agar kelestariannya tetap terjaga. Mereka juga menginginkan keikutsertaan atau turut berpartisipasi dalam program-program pemerintah baik dari lingkup dusun/desa sampai pemerintah daerah dalam pengelolaan kawasan mangrove yang lestari. Hasil wawancara dan FGD yang dilakukan di teluk Kotania juga menunjukkan sebahagian besar masyarakat sangat antusias untuk menjaga dan melestarikan kawasan mangrove. Ini memberikan indikasi yang sangat penting dalam pengelolaan kawasan mangrove yang lestari.

Masyarakat pesisir teluk Kotania setuju bahwa; 1) Perlu adanya aturan dalam pengelolaan kawasan mangrove, dan 2) Pelanggaran terhadap aturan pengelolaan kawasan mangrove perlu diberikan sangsi atau hukuman. Pengetahuan masyarakat selama ini sangat kurang tentang adanya aturan dan sangsi dalam pengelolaan kawasan mangrove. Melalui penelitian ini masyarakat setuju apabila pemerintah daerah membuat suatu aturan secara tertulis dalam pengelolaan kawasan mangrove. Mereka juga sepakat untuk mentaati aturan yang dibuat untuk menjaga kelestarian kawasan mangrove dan apabila mereka melanggar aturan tersebut mereka bersedia dikenakan sangsi atau hukuman. Selama ini pemerintah daerah melalui instansi terkait dengan wilayah pesisir seperti Dinas Perikanan dan Kelautan, Badan Lingkungan Hidup dan Dinas Kehutanan Kabupaten Seram Bagian Barat.

Namun untuk kriteria penilaian persepsi terhadap; 1) Bentuk pengelolaan tidak harus sesuai dengan kearifan lokal (adat istiadat/budaya) yang dimiliki penduduk setempat, 2) Pengelolaan kawasan mangrove di Teluk Kotania akan menghambat pembangunan wilayah pesisir dan laut. Misalnya: pembangunan perumahan penduduk dan lahan pertanian akan terhambat, 3) Pengelolaan kawasan mangrove akan membatasi penduduk setempat untuk memanfaatkan mangrove maupun sumber daya yang ada didalamnya masyarakat masih ragu-ragu untuk memberikan penilaian. Hasil analsis ketiga kriteria penilaian ini menunjukkan masyarakat selama ini hanya memanfaatkan keberadaan kawasan mangrove tanpa adanya aturan dan sangsi sehingga mereka bebas memanfaatkan kawasan mangrove beserta ekosistemnya. Hal ini sangat terlihat dari pengamatan lapangan dimana kawasan mangrove sebahagian besar rusak akibat ulah manusia. Mereka menebang pohon mangrove untuk dimanfaatkan sebagai bahan bakar, konstruksi rumah dan peralatan rumah tangga. Sebahagian pohon mangrove ditebang untuk membangun rumah penduduk yang berada diperbatasan darat dan pantai. Masyarakat ragu-ragu untuk menjawab ketiga kriteria ini karena mereka juga sangat membutuhkan pohon mangrove untuk menunjang kehidupan mereka sehari-hari. Perusakan yang dilakukan terutama disebabkan tekanan ekonomi (Muryani et al., 2011). Selama ini masyarakat di teluk Kotania kurang adanya pengetahuan tentang keberadaan kawasan mangrove serta manfaatnya dan upaya-upaya yang harus dilakukan untuk melestarikan kawasan mangrove, sehingga penilaian masyarakat masih ragu.

Masyarakat pesisir teluk Kotania setuju bahwa; 1) Hanya sebagian penduduk setempat atau pemerintah saja yang akan memperoleh manfaat/keuntungan atas adanya pengelolaan kawasan mangrove di Teluk Kotania, dan 2) Masyarakat pendatang tidak perlu menaati aturan dalam pengelolaan kawasan mangrove di Teluk Kotania. Kedua kriteria penilaian ini juga didasarkan atas kurangnya pengetahuan masyarakat terhadap pengelolaan kawasan mangrove yang sangat bernilai ekonomi maupun ekologi bagi masyarakat.

Penilaian persepsi masyarakat terhadap pengelolaan kawasan mangrove juga sangat dipengaruhi oleh tingkat pendidikan dan pengetahuan masyarakat. Pengelolaan kawasan mangrove di teluk Kotania harus dapat dilaksanakan dengan baik. Kondisi ini akan sangat mendukung pelestarian kawasan mangrove secara berkelanjutan. Masyarakat pada 


\section{Analisis Persepsi Masyarakat terhadap Pengelolaan Kawasan Mangrove Teluk Kotania}

umumnya harus diberikan pengetahuan berupa penyuluhan dan pelatihan terhadap pengelolaan kawasan mangrove demi kelestarian kawasan mangrove. Mengingat rentannya keberadaan hutan mangrove dan aktivitas masyarakat yang tinggal di sekitar hutan mangrove dalam menjaga sumberdaya alamnya, maka peranan masyarakat dalam menjaga kelestarian bahkan mengembangkan hutan mangrove menjadi suatu hutan lingkungan pendukung ketersediaan sumberdaya alam laut menjadi sangat penting (Cie et al., 2010). Persepsi masyarakat perlu diarahkan untuk selalu menajaga dan melestarikan keberadaan kawasan beserta ekosistem mangrove.

\section{Kesimpulan dan Rekomendasi}

\section{Kesimpulan}

Berdasarkan hasil penelitian, analisis data yang dilakukan dan pembahasan maka dapat ditarik beberapa kesimpulan antara lain :

1. Masyarakat pesisir di teluk Kotania sangat setuju bahwa; 1) Kawasan mangrove di Teluk Kotania saat ini perlu/penting untuk dikelola agar dapat lestari, 2) Bentuk pengelolaan kawasan mangrove yang dilakukan harus melibatkan seluruh penduduk setempat, 3) Perlu adanya kerjasama antara pemerintah dan penduduk setempat dalam kegiatan pengelolaan kawasan mangrove.

2. Masyarakat pesisir teluk Kotania setuju bahwa; 1) Perlu adanya aturan dalam pengelolaan kawasan mangrove, dan 2) Pelanggaran terhadap aturan pengelolaan kawasan mangrove perlu diberikan sangsi atau hukuman.

3. Masyarakat pesisir teluk Kotania ragu-ragu bahwa; 1) Bentuk pengelolaan tidak harus sesuai dengan kearifan lokal (adat istiadat/budaya) yang dimiliki penduduk setempat, 2) Pengelolaan kawasan mangrove di Teluk Kotania akan menghambat pembangunan wilayah pesisir dan laut. Misalnya: pembangunan perumahan penduduk dan lahan pertanian akan terhambat, 3) Pengelolaan kawasan mangrove akan membatasi penduduk setempat untuk memanfaatkan mangrove maupun sumber daya yang ada didalamnya masyarakat masih ragu-ragu untuk memberikan penilaian.

4. Masyarakat pesisir teluk Kotania setuju bahwa; 1) Hanya sebagian penduduk setempat atau pemerintah saja yang akan memperoleh manfaat/keuntungan atas adanya pengelolaan kawasan mangrove di Teluk Kotania, dan 2) Masyarakat pendatang tidak perlu menaati aturan dalam pengelolaan kawasan mangrove di Teluk Kotania.

\section{Rekomendasi}

Rekomendasi dari penelitian ini adalah :

1. Masyarakat pesisir di teluk Kotania harus diberikan pengetahuan tentang pentingnya manfaat mangrove dan pengelolaan kawasan mangrove secara lestari.

2. Masyarakat perlu dilibatkan bersama-sama dengan pemerintah dalam pengelolaan kawasan mangrove secara lestari.

3. Aturan dan sangsi perlu dibuat dalam suatu atruan tertulis berupa Perda atau Perdes untuk pengelolaan kawasan mangrove.

\section{Daftar Pustaka}

Arikunto, S., 2010. Prosedur Penelitian, Suatu Pendekatan Praktik. Edisi Revisi. Penerbit Rineka Cipta. 413 p. 
Cie, Y., Wisudo, S. H., dan Purbayanto, A., 2010. Partisipasi Masyarakat Nelayan Dalam Pemanfaatan Kawasan Mangrove Untuk Perikanan Tangkap Di Halmahera Utara. http://www. repository.ipb.ac.id. 10 September 2012.

Dahuri, H. R., J. Rais, S. P. Ginting dan M. J. Sitepu. 2004. Pengelolaan Sumber Daya Wilayah Pesisir dan Lautan Secara Terpadu. Jakarta: PT Pradnya Paramita,

Ernawati, 1997. Metode Statistika. Transito, Bandung.

Fauzi, A., dan Anna S. 2005. Permodelan Sumberdaya Perikanan dan Kelautan Untuk Analisis Kebijakan. Jakarta: Penerbit PT. Gramedia Pustaka Umum

Harahap, N. 2010. Penilaian Ekonomi Hutan Mangrove dan Aplikasinya Dalam Perencanaan Wilayah Pesisir. Graha Ilmu. 254 p.

Mulyadi, S. 2007. Ekonomi Kelautan. Penerbit PT. Raja Grafindo Persada. 223 hal.

Muryani, C., Ahmad, Nugraha, S., dan Utami, T., 2011. "Model Pemberdayaan Masyarakat Dalam Pengelolaan Dan Pelestarian Hutan Mangrove Di Pesisir Pasuruan Jawa Timur, J Jurnal Manusia dan Lingkungan. LPPM UGM.

Nanlohy, H., 2013. "Valuasi Ekonomi Ekosistem Mangrove Di Negeri Waiheru Kota Ambon.” J. Pena. Jurnal Ilmu Pengetahuan dan Teknologi, 25 (1) : p. 15-21.

Nanlohy, H., Azis, N. B., Ambaryanto, Sahala H., 2013. "Economic Value Analysis for Mangroves ecosystem Use in Kotania Bay," International Conference on Regional Development; Conference Proceeding, p. 195-199.

Nikijuluw, V. P. H., 2002. Rezim Pengelolaan Sumberdaya Perikanan. PT Pustaka Cidesindo, Jakarta.

Nontji, A., 2000. Laut Nusantara. Penerbit Djambatan, Jakarta. 367 P.

Supriharyono, 2009. Konservasi Sumberdaya Hayati di Wilayah Pesisir dan Laut Tropis. Penerbit Pustaka Pelajaran. $470 \mathrm{p}$.

Soukotta, L. M., 2013. "Valuasi Ekonomi Ekosistem Mangrove Di Negeri Tawiri Kota Ambon.” J. Pena. Jurnal Ilmu Pengetahuan dan Teknologi, 25 (1) : p. 8-14.

Talakua, W., 2013. “Valuasi Ekonomi Ekosistem Mangrove Di Negeri Passo Kota Ambon”. J. Pena. Jurnal Ilmu Pengetahuan dan Teknologi, 25 (1) : p. 1-7.

Tuwo, H. A., 2011. Pengelolaan Ekowisata Pesisir dan Laut, Pendekatan Ekonomi, Sosial Ekonomi, dan Sarana Wilayah. Penerbit Brilian Internasional. $412 \mathrm{p}$.

Umar, H. 2005. Riset Sumber Daya Manusia dalam Organisasi. PT Gramedia. Pustaka Utama, Jakarta. 
98 Analisis Persepsi Masyarakat terhadap Pengelolaan Kawasan Mangrove Teluk Kotania

JURNAL WILAYAH DAN LINGKUNGAN, 2 (1), 89-98 